논 문 17-2-20

\title{
$\mathrm{Fe}-$ Phthalocyanine을 이용한 Carbon Nanofiber의 저온합성과 전계전자방출 특성
}

\section{Field Emission Character and Low Temperature Synthesize of Carbon Nanofibers using Fe-phthalocyanine}

\author{
류정탁 ${ }^{1 . a}$, T. Ikuno ${ }^{2}$, M. Katayama ${ }^{2}$, K. Oura ${ }^{2}$ \\ (Jeong-Tak Ryu ${ }^{1 . a}$, T. Ikuno ${ }^{2}$, M. Katayama ${ }^{2}$, and K. Oura ${ }^{2}$ )
}

\begin{abstract}
Using Ar plasama and Fe-phthalocyanine, carbon nanofibers have been synthesized at a low temperature. Fe-phthalocyanine was used as a source material for this process. The carbon nanofibers were grown in random orientation with a diameter of about $100 \mathrm{~nm}$ and length up to $10 \mathrm{\mu m}$ on $\mathrm{Si}$ substrate. The synthesized carbon nanofibcrs exhibited excellent field - emission characteristics. Protrusions with a nanometer size are observed at an angle of $60^{\circ}$ with respect to the nanofiber axis. Furthermore, we found the selective growth of nanofibers on a scratched substrates.
\end{abstract}

Key Words : Carbon nanofiber, Low temperature growth, Fe-phthalocyanine, Field emission

\section{1. 서 론}

카본나느튜브(carbon nanotube : CNT)[1,2], 카 본나노파이버(carbon nanofiber : $\mathrm{CNF}$ )[3,4], 다이 아몬드, 다이아몬 I스앙카본(DLC)[5,6], 비정질카본박 막(a-C)[7,8] 뜽과 같은 카본 관련 재도늘은 최군 가장 많은 관심을 모으고 있는 재료라 할 수 있다. 이것은 카본 관련 재료들이 가지고 있는 물리적, 화학적, 기계적 특성들 때문이다. CNT 및 CNF는 아크방전법 (arc discharge)[9], 레이저 긍착법 (laser vaporization)[10], 열적 화학증착법(thermal chemical vapor deposition[11], 그리고 플라즈마 CVD (plasma enhanced chemical vapor depositin

1. 대구대학교 정보통신공학부

(경북 경산시 진량읍 내리리 15)

2. 일본 Osaka University

a. Corresponding Author : jryu@taegu.ac.kr

접수일자 : 2003. 8. 13

1차 심사: 2003. 10.6

심사완료 : 2003. 12. 16
: PECVD)[12] 등과 같이 여러 가지 방법에 의해서 합성이 된다. 이풀 방법중 CVD에 의한 방법은 카 본나노구조의 합성을 위하여 가장 많이 사용되는 방법이다. 이러한 방법을 사용할 경우 나노튵브와 같은 나노구조뚤을 합성하기 위해서는 촉매 금속 의 사용은 필수적인 것이다. 따라서 촉매금속이 어 떻게 기판 위에 분포하는가에 따라서 나노구조물 은 매우 다른 합성 톡성을 보인다. 촉매금속의 종 류, 양, 형태, 고리고 분포 밀도는 카본나노구조물 의 크기와 밀도, 성장방향성에 큰 영향을 준다. 또 한 카본나노고조뚤의 합성 절차에서도 촉매금속의 합성방법에 따라 카본나조구조문의 특성에도 영향 을 준다.

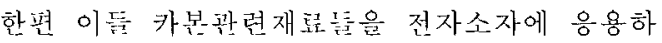
기 위해서 여러 가지 문제점들을 나열할 수 있다. 특히 $\mathrm{CNT}$ 및 $\mathrm{CNF}$ 의 경우 카본나노구조물의 밀도. 와 배항성 고리고 합성온도를 비롯한 합성 조건 뜽이 있다. 카본나노구꿀의 밀도와 배향성에 관한 연구는 국내 및 죽외 연구자들에 의해 많은 연구 
가 수행되어 좋은 성과가 최근 발표되고 있다 [13,14]. 그러나, 합성온도에 관한 실험결과는 아직 까지 좋은 결과를 보이지 않고 있다. 특히 최근 전 자소자의 제작에 있어 저온화의 경향은 무시할 수 없는 추세이다. 이것은 나노튜브롤 이용하여 전자 소자를 체작함에 있어서 기판으로 사용되는 물질 이 나노튜브 합성 온도에서 견딜 수 있는 재료가 아니기 때문이다. 따라서 카본나노구조물의 저온합 성은 미래 전자소자의 응용과 개발을 위해 매우 중요한 과제이다.

본 연구에서는 카본나노퐈이버(CNF)의 저온 합 성을 위하여 금속유기물과 $\mathrm{Ar}$ 플라즈마를 사용하 였다. $\mathrm{Ar}$ 폴라즈마는 금속유기물의 열적 분해를 위하여 사용되었으며 금속유기물은 $\mathrm{CNF}$ 의 합성을 위해 필수적인 촉매 금속과 탄소원자의 생성을 위 해 사용되었다. 본 연구에서는 이러한 촉매금속이 포함되어 있는 금속유기물을 사용하므로 나노구조 물 합성시 촉매금속의 합성 단계롤 생략할 수 있 는 이점이 있다.

\section{2. 실 험}

본 연구에서는 $\mathrm{CNF}$ 의 저온 합성을 위하여 특수 하게 제작된 $\mathrm{DC}$ 플라즈마 발생 장치롤 사용하였 다. 폴라즈마는 특수 제작된 아노드전극과 $\mathrm{DC}$ 전 원이 공급된 텅스텐 필라멘트 사이에 형성되어진 다. 기판은 아노드 전극 위에 놓여졌으며 그 기판 위에는 약 $10 \mathrm{mg}$ 의 Fe-phthalocyanine $\left(\mathrm{FeC}_{32} \mathrm{H}_{16} \mathrm{~N}_{8}: \mathrm{FePC}\right)$ 분말이 놓여졌다. 이렇게 놓 여진 금속유기물분말은 폴라즈마에 의해 열분해 되어 $\mathrm{CNF}$ 의 합성을 위한 촉매금속과 탄소원자를 생성하게 된다. 터보분자펌프에 의해 챔버 전체를 $1 \times 10^{6}$ Torr로 만든 다음 필라멘트를 $1500^{\circ} \mathrm{C}$ 의 온 도가 되게 전류를 공급하였다. 그 후 $\mathrm{Ar}$ 가스를 $7.8 \times 10^{3}$ Torr이 될 때까지 챔버 속에 주입하였다. 그리고 필라멘트와 아노드 전극 사이에는 $\mathrm{Ar}$ 플라 즈마를 생성시키기 위하여 $+50 \mathrm{~V}$ 의 전압을 인가 하였다. $\mathrm{CNF}$ 룰 합성하는 동안의 기판 온도는 약 $400^{\circ} \mathrm{C}$ 였다. 이 온도는 적외선 온도계와 기판 뒷면 에 부착된 열전대에 의하여 측정되었다.

본 연구에서 사용된 기판은 $\mathrm{P}$ 이 도핑된 $\mathrm{N}$ 형의 $\mathrm{Si}(100)$ 웨이퍼가 사용되었다. $\mathrm{Si}$ 기판은 아세톤에 의한 초음파 세척을 10 분간 한 후 $10 \% \mathrm{HF}$ 을 이용 하여 기판 위에 형성되어 있는 자연 산화막을 제 거하였다.
합성된 CNF의 형태와 구조는 scanning electron microscopy(SEM)와 transmission electron microscopy (TEM)에 의하여 관찰되어졌다. 그리 고 전계전자방출 특성은 $5 \times 10^{10}$ Torr의 초고진공 장비 안에서 측정되었다. 그림 1 은 본 연구에서 사 용된 전계전자방출 특성평가 장비의 개략도이다. $\mathrm{CNFs}$ 로부터 방출되는 전자를 집속하기 위하여 직 경 $14 \mathrm{~mm}$ 의 스테인레스 봉을 사용하였다. 그리고 CNFs와 아노드 사이의 거리는 약 $200 \mu \mathrm{m}$ 로 유지 하여 전계전자 방출특성을 계측하였다.

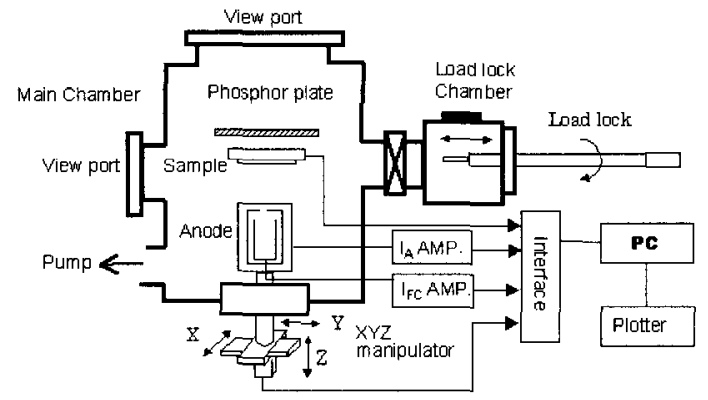

그림 1. 전계방출톡성 측정 장비의 개략도.

Fig. 1. Schematic illustration of the field emission measurement profiler.

\section{3. 결과 및 고찰}

그림 2(a)에 $\mathrm{Si}$ 기판 위에 합성된 carbon nanofiber의 SEM 관찰 결과를 보었다. 합성된 $\mathrm{CNFs}$ 는 $\mathrm{Si}$ 기판 전체에 불규칙하게 분포되어 있 는 것을 알 수 있다. $\mathrm{CNFs}$ 의 형태는 나선형과 직 선형으로 여러 종류가 관측된다. 그리고 어느 특정 한 곳에서부터 자라 마치 전체적으로 퍼져나가는 모습으로 보인다. $\mathrm{SEM}$ 의 결과로부터 $\mathrm{CNFs}$ 의 밀 도는 $10 \% \mathrm{~cm}^{2}$ 이었다. 그리고 $\mathrm{CNFs}$ 의 직경은 50 $100 \mathrm{~nm}$ 의 분포를 가졌으며 길이는 $10 \mu \mathrm{m}$ 이상이었 다.

그림 2(b)에 CNFs의 끝 부분에 대한 TEM 관 찰 결과를 보였다. $\mathrm{CNFs}$ 의 벽 주위에는 중심 축을 기준으로 하여 약 $60^{\circ}$ 각도로 나노 크기의 돌기가 형성되어 있는 것을 볼 수 있다. 이런 돌기형태는 전계집중현상의 한 요인이 될 것이며 이로 인한 전계전자방출특성에 큰 영향을 줄 것이다.

그림 3(a)에 본 실험에서 합성된 $\mathrm{CNFs}$ 에 의해 
얻어진 전계전자방출특성을 나타내었다. 즉 인가 전계 값에 대한 방출전류밀도이다. $0.1 \mathrm{~mA} / \mathrm{cm}^{2}$ 의 전류 밇도를 얻기 위해 필요한 전계 값을 임계전 계값 $\mathrm{E}_{\mathrm{th}}$ 라 하였을 때 본 실헙에서 얻어진 임계전 계값은 약 $2.4 \mathrm{~V} / \mathrm{\mu m}$ 이었다. 아크 방전에 의해 합 성된 single wall nanotube (SWNT)의 경우에는 약 $2.2 \mathrm{~V} / \mathrm{um}[15]$, Microwave plasma CVD에 의하 여 합성된 multi wall nanotube (MWNT)의 경우 예는 약 $1.8 \mathrm{~V} / \mathrm{\mu m}[16]$ 그리고 나노구조카본 박막 의 경우 $3.0 \mathrm{~V} / \mu \mathrm{m}[17]$ 의 값이 필요하다는 보고와 비교하였을 때 본 연구에서 얻어진 $\mathrm{CNFs}$ 의 전계 전자방출특성은 우수한 특성을 보인다.
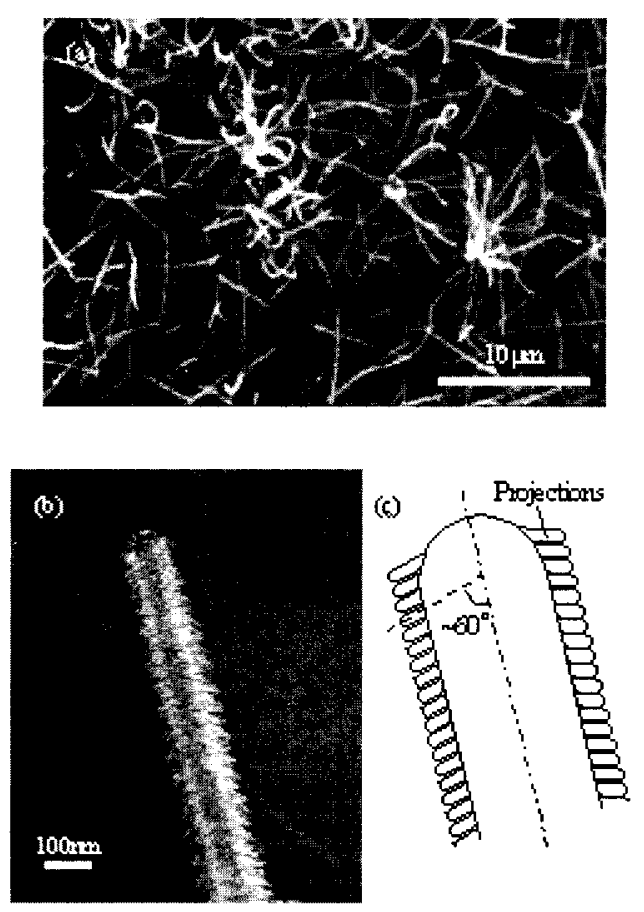

그림 2. (a) $\mathrm{Si}$ 기판 위에 합성된 $\mathrm{CNF}$ 의 $\mathrm{SEM}$ 관 찰 결과. (b) 선택된 $\mathrm{CNF}$ 의 $\mathrm{TEM}$ 관찰 결과. (c) $\mathrm{TEM}$ 에 의한 $\mathrm{CNF}$ 의 모식도.

Fig. 2. SEM image of CNF on Si substrate (a) , TEM image of a tip of a CNF (b) and schematic illustration of $\mathrm{CNF}$ structure (c). The CNFs have range of $50 \sim 100 \mathrm{~nm}$ in diameter and range of over $10 \mathrm{~mm}$ in length, which were randomly oriented to the substrate.

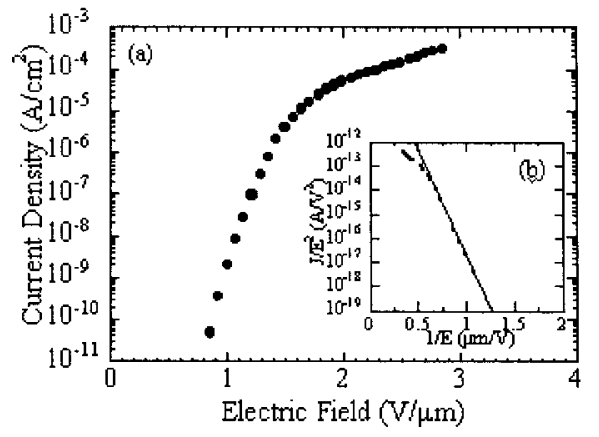

그림 3. $\mathrm{CNF}$ 에 의해 엍어진 전계전자방출특성 (a) 인가전압에 대한 방출전류밀도 (b) Fowler-Nordheim plot.

Fig. 3. Field emission characteristic of deposited CNF. Emission current density vs. applied electric field is (a) and Fowler-Nordheim plot is (b).

전계전자방출은 일반적으로 Fowler-Nordheim 이론에 의해 모델링할 수 있다[18].

$$
J=\frac{a(\beta E)^{2}}{\psi} \exp \left(\frac{-b \psi^{3 / 2}}{\beta E}\right)
$$

여기서 $\beta$ 는 기하학적인 전계강화인자이며, $\Psi$ 는 일함수이다. 그리고 $\mathrm{E}[\mathrm{V} / \mathrm{\mu m}]$ 는 인가 전계값이며, $\mathrm{a}$ 와 $\mathrm{b}$ 는 상수이다.

그림 3(b)에 그림 3(a)의 실험결과에 대한 Fowler-Nordheim plot 결과를 보였다. Fowler-Nordheim plot는 강한 직선 형태를 보이고 있으며 이것은 그림 3(a)에서 언어진 결과가 전형 적인 전계전자방출에 의한 것임을 이론적으로 증명 하는 것이다. 그리고 Fowler-Nordheim plot의 기울 기로부터 재료의 일함수값을 구할 수 있다. 만약 기하학적인 전계 강화 요소 (geometric field enhancement factor) $\beta$ 값을 1로 하였을 때 본 연구 에서 얻어진 $\mathrm{CNFs}$ 의 일함수 값은 약 $0.02 \mathrm{eV}$ 이하 의 값을 가지는 것으로 판단된다. 그러나 위의 수 식의 $\beta$ 값은 기하학적인 값으로 평탄한 재료에서보 다는 바늘과 같이 끝이 뽀족한 경우에 전계가 더욱 집중하게 되어 그 값은 증가한다. 본 연구에서 얻 어진 $\mathrm{CNFs}$ 의 경우 그림 2에서와 같이 지금까지 보 고된 나노튜브의 형태와는 달리 CNFs의 양벽에는 똘기가 형성이 되어 있어 방출전류밀도의 양을 증 가시킬 것이다. 따라서 본 연구에서 얻어진 $\mathrm{CNFs}$ 
(a)
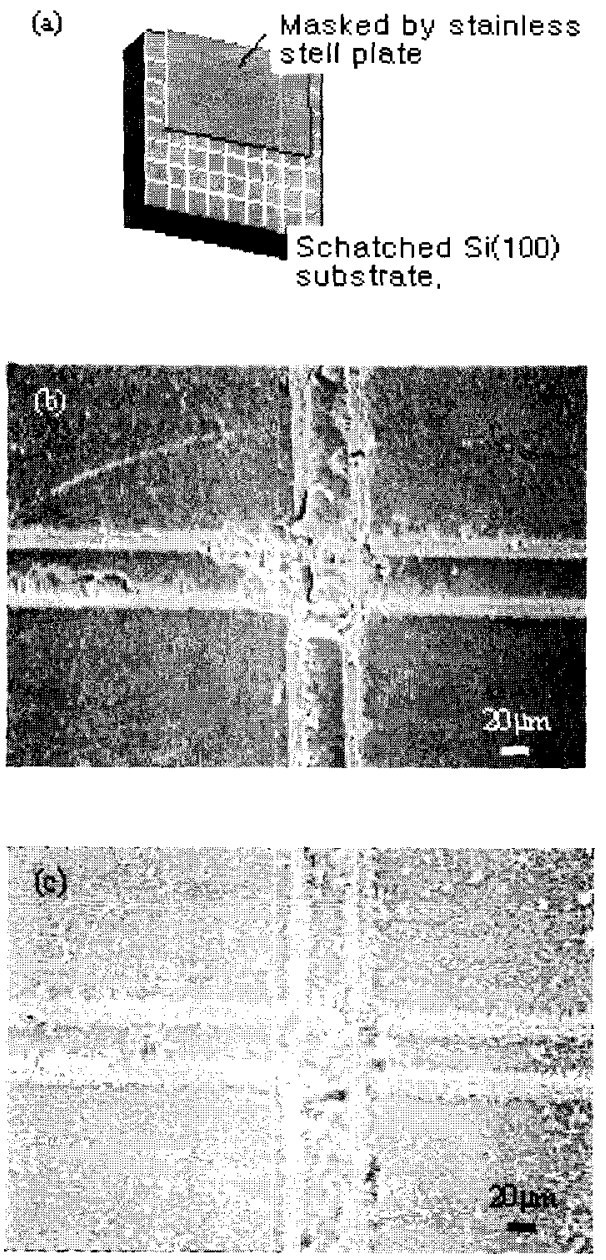

그림 4. (a) $\mathrm{CNF}$ 의 선택성장 확인을 위해 준비된 $\mathrm{Si}$ 기판의 모략도. 다이아몬드 칼에 의해 $\mathrm{Si}$ 기판을 일정 간격으로 자국을 남겼으 며 $\mathrm{Si}$ 기판의 일부폴 국속판으로 마스크 하였음. (b) 듬속판에 의한 마스크된 영 역, (c) 마스크에서 노출된 $\mathrm{Si}$ 기판으로 $\mathrm{CNF}$ 가 집중적으로 합성되어 있음.

Fig. 4. Schematic diagram of substrate preparation, a half area of $\mathrm{Si}$ substrate was masked by stainless steel plate(a), surface morphology of masked area(b) and exposed area (c), CNFs densely grew on scratched region.
의 우수한 전계전자방출 특성은 그림 $2(\mathrm{~b})$ 에서 보 여진 CNFs 주위에 붙어 있는 길이 $30 \mathrm{~nm}$, 폭이 $10 \mathrm{~nm}$ 의 돌기 때문으로 추정된다. 이 돌기부분은 인가된 전계를 $\mathrm{CNFs}$ 에 더욱 집중시키므로 일반의 $\mathrm{CNF}$ 에 비하여 더 많은 전류밀도를 방출할 것으로 추론된다. 그리고 $\mathrm{CNFs}$ 가 기판 전체에 불규칙적으 로 분포하고 있음을 고려해 볼 때 이 돌기의 영향 으로 기판 전체에 걸쳐서 전자가 방출될 것으로 예 상할 수 있다. 반면 전계전자방출의 전체적이 효율 적인 면에서 기판 전체에 무질서하게 $\mathrm{CNFS}$ 가 분포 하는 것은 종은 경향이 아닐 것이다. 따라서 $\mathrm{CNFs}$ 의 선택적 성장은 소자의 응용면에서 필요하다.

그림 4(a)에 선택적 성장의 확인을 위해 특수하 게 설치한 $\mathrm{Si}$ 기판의 모략도를 보였다. $\mathrm{Si}$ 기판에 는 다이아몬드 팬에 의하여 그림과 같이 자국을 남겼으며 또한 스테인레스 조각을 이용하여 $\mathrm{Si}$ 기 판의 일부를 가려 $\mathrm{CNFS}$ 합성을 시도하었다. 그림 4(b)와 (c)는 스테인레스 조각에 의하여 마스크된 영역과 마스크 되지 않은 영역의 $\mathrm{SEM}$ 관찰 결과 를 각각 보이고 있다. 그림 4(c)에서 보여지는 것 과 같이 CNFs는 다이아몬드 팬에 의해서 남겨진 홈 사이에 집중적으로 분포하고 있음을 알 수 있 다. CNFs가 합성될 대 금속 유가물은 폴라즈마에 으해 탄소, 질소, 금속 원자 및 분자로 분리되어 진다. 이렇게 분리된 $\mathrm{Fe}$ 원자는 기판 온도 $400^{\circ} \mathrm{C}$ 에 의하여 대부분의 홈 사이로 이동하여 분포하게 되 므로 이 영역예서 $\mathrm{CNFs}$ 가 집중적으로 합성된 것 으로 추정할 수 있다.

\section{4. 결 론}

일반적으로 carbon nanotube를 합성하기 위해서 는 $600^{\circ} \mathrm{C}$ 이상의 온도가 필요하뗘 또한 별도의 촉 매 금속 증착 과정이 필요하다. 그러나 본 연구에 서는 금속유기물을 사용하므로 촉매 금속 증착의 공정과정을 생략하였으며 또한 합성 온도도 $400^{\circ} \mathrm{C}$ 로 저온화 하였다. 합성된 $\mathrm{CNF}$ 의 직경은 50 $100 \mathrm{~nm}$ 의 분포를 가졌으며 길이는 $10 \mu \mathrm{m}$ 이상이있 다. $\mathrm{CNF}$ 는 매우 높은 선택성장 특성을 보였다.다 이아몬드 팬에 의하여 $\mathrm{CNF}$ 합성 전 기판 위에 표 시된 홈 주위에 $\mathrm{CNF}$ 는 집중적으로 합성되어 높은 밀도 분포를 보였다. 또한 $\mathrm{CNF}$ 는 높은 전계전자방 출특성을 보였다. 


\section{감사의 글}

이 논문은 2002 년 학술진홍재단의 공모과제 연 구비에 의하여 연구되었음(KRF-2002-042-D00100).

\section{참고 문헌}

[1] Ray H. Baughman, Anvar A. Zakhidov, Walt and A. de Heer, "Carbon nanotubes the route toward applications", Science, Vol 297, No. 2, p. 787, 2002.

[2] 김광식, 류호진, 장건이, “유도결합형 폴라즈 마 화학기상증착법에서 탄소나노튜브의 수직 성장과 전계방출 특성 향상 연구”, 전기전자 재료학회논문지, 15권, 8호, p. 713, 2002.

[3] K. Kamada, T. Ikuno, S. Takahashi, T. Oyama, T. Yamamoto, M. Kamizono, S. Ohkura, S. Honda, M. Katayama, T. Hirao, and K. Oura, "Surface morphology and field emission characteristics of carbon nanofiber films grown by chemical vapor deposition on alloy catalyst", Applied Surface Science, Vol. 212-213, No.15, p. 383, 2003.

[4] Xiaoqi Yan, Xueping Gao, Ying Li, Zhanquan Liu, Feng Wu, Yutian Shen, and Deying Song, "The surface decoration and electrochemical hydrogen storage of carbon nanofibers", Chemical Physics Letters, Vol. 372 , No. $3-4$, p. 336,2003

[5] Hae-Suk Jung, Hyung-Ho Park, Seong Sik Pang, and Sang Yeol Lee, "The structural and electron field emission characteristics of pulsed laser deposited diamond-like carbon films with thermal treatment", Thin Solid Films Vol. 355/356 p. 151, 1999.

[6] Kyung-Suk Shim, Sang, and Yeol Lee, "Deposition and characterization of tribologic DLC thin films fabricated by pulsed laser deposition", J. of KIEEME, Vol. 12, No. 5, p. 456, 1999.

[7] Yeon-Bo Kim, Jeong-Tak Ryu, and K Oura, "Field electron emission from amorphous carbon thin film grown using RF Magnetron sputtering method", J. of
KIEEME(in Korean), Vol. 14, No. 3, p. 234, 2000

[8] 류정탁, Kenjiro Oura, 김연보, “레이저 증착 법에 의한 탄소계 박막의 구조 및 전계방출 톡성", 전기전자재료학회논문지, 15권, 7호, p. 634, 2002.

[9] C. Journet, W.K.Maser, P. Bernier, A Loiseau, M. Lamy de la Chapelle, S. Lefrant, P. Deniard, and R. Lee, J .E. Fischer, "Large-scale production of single-walled carbon nanotubes by the electric-arc technique", Nature, Vol. 388, p. 756, 1997.

[10] W. Zhu, C. Bower, O. Zhou, G. Kochanski, and S. Jin, "Large current density from carbon nanotube field emitters", Appl. Phys. Lett., Vol. 75, p. 873. 1999.

[11] S. Fan, G. Michael, G. Chapline, N. R. Franklin, T. W. Tombler, A. M. Cassell, and H. Dai, "Self-Oriented Regular Arrays of Carbon Nanotubes and Their Field Emission Properties", Science Vol. 283, p. 512, 1999.

[12] S. H. Tsai, C. W. Chao, C. L. Lee, H. and C. Shih, "Bias-enhanced nucleation and growth of the aligned carbon nanotubes with open ends under microwave plasma synthesis", App, Phys. Lett., Vol. 74, p. 3462, 1999.

[13] L. Kilsson, O. Groening, C. Emmenegger, O. Kuettel,E. Schaller, and L. Schlapbach, H. Kind,J-M. Bonard, and K. Kern, "Scanning field emission from patterned carbon nanotube films", Applied physics letters, Vol. 76 , No. 15 , p. 2071, 2000

[14] Y. Huh, J. Y. Lee, J. H. Lee, T. J. Lee, S. C. Lyu, and C. J. Lee, "Selective growth and field emission of vertically well-aligned carbon nanotubes on hole-patterned silicon substrates", Chemical Physics Letters, Vol. 375, No. 3-4, p. 388, 2003.

[15] J. M. Kim, W. B. Choi, N. S. Lee, J. E. Jung, "Field emission from carbon nanotubes for displays", Diamond, and 
Relat. Ma.,. Vol. 9, p. 1184, 2000.

[16] H. Murakami, M. Hirakawa, C. Tanaka, and H. Yamakawa, "Field emission from well-aligned, patterned, carbon nanotube emitters", Appl. Phys, Lett., Vol. 76, p. 1776, 2000.

[17] A. N. obraztov, A. P. Wolkov, I. Pavlovsky, "Field emission from nanostructured carbon materials", Diamond and Relat. Mat., Vol. 9, p. 1190,2000

[18] J. P. Xanthakis, and A. Modinos, "A theoretical model of electron emission from amorphous carbon nitride films", Diamond, and Relat. Mat., Vol. 8, p. 798, 1999. 